\title{
ENTRE MUROS: \\ A Vinculatividade Judicial vs. o Princípio da Independência dos Tribunais
}

\author{
http://dx.doi.org/10.21527/2176-6622.2019.52.6-20
}

Recebido em: 19/5/2019

Modificações requeridas em: 1ㅇ/10/2019

Aceito em: 26/10/2019

\section{André Luiz Staack}

Doutorando em Ciências Jurídicas pela Universidade do Minho (Portugal). Mestre em Ciência Jurídica pela Universidade do Vale do Itajaí - Univali. Mestre em Estudos Políticos pela Universidade de Caldas UCaldas/Colômbia. Especialista em Direito Penal e Processual Penal pela Univali (convênio com a Escola do Ministério Público de Santa Catarina). Bacharel em Direito pelo Centro Universitário de Brusque. Oficial de Justiça e avaliador lotado no Fórum da Comarca de Brusque/SC. Professor e Coordenador da Comissão Própria de Avaliação, do Núcleo de Programas de Extensão e do Núcleo de Iniciação Científica na Faculdade do Vale do Itajaí Mirim - Brusque/SC. http://lattes.cnpq.br/5640235906331706. staack@tjsc.jus.br

\section{RESUMO}

Este artigo objetivou identificar melhor a relação entre a vinculatividade judicial e o princípio da independência dos tribunais. Para o alcance do objetivo proposto, o método de abordagem foi o indutivo, sendo o levantamento de dados realizado por meio da técnica da pesquisa bibliográfica de fonte secundária. Nas considerações finais, concluiu-se que a melhor relação entre a vinculatividade judicial e o princípio da independência dos tribunais resta estabelecida no modelo português, uma vez que ela permite ao magistrado uma ampliação de sua percepção imaginativa e, por consequência, auxilia na formação de um direito mais coerente.

Palavras-chave: Vinculatividade judicial. Princípio da independência dos tribunais. Civil Law. Common Law.

\section{BETWEEN WALLS: JUDICIAL BINDING VS. THE PRINCIPLE OF THE INDEPENDENCE OF THE COURTS}

\section{ABSTRACT}

This article aimed to identify the best relationship between judicial binding and the principle of the independence of the courts. In order to reach the proposed objective, the method of approach was the inductive one, being the data collection carried out through the technique of bibliographic research of secondary source. In the final considerations, it was concluded that the best relationship between judicial binding and the principle of the independence of the courts, remains established in the portuguese model, since it allows the judge an expansion of his imaginative perception and, consequently, helps in the formation of a more coherent Law.

Keywords: Judicial binding. Principle of the independence of the courts. Civil Law. Common Law.

\section{SUMÁRIO}

1 Introdução. 2 The Binding Element: A Vinculatividade e sua Alocação nos Subsistemas que Compõem a Família Jurídica Ocidental. 3 A Vinculatividade Judicial à Brasileira. 4 A Experiência Portuguesa dos Assentos: Rumo à Vinculatividade Judicial Mitigada. 5 A Vinculatividade Judicial e a Independência dos Tribunais. 6 Conclusão. 7 Referências. 


\section{INTRODUÇÃO}

Este artigo visa a identificar a melhor a relação entre a vinculatividade judicial e o princípio da independência dos tribunais.

O critério metodológico utilizado para essa investigação e a base lógica do relato dos resultados apresentados residem no método indutivo. Na fase de tratamento dos dados utilizou-se o método cartesiano.

Este texto, portanto, tem como objetivo geral identificar a melhor a relação entre a vinculatividade judicial e o princípio da independência dos tribunais. São objetivos específicos: a) abordar sobre a vinculatividade (the binding element) nos subsistemas anglo-saxônico e romano-germânico, dando ênfase a sua relação com a via judicial; b) versar, a título de exemplo, sobre a realidade jurídica brasileira, dando destaque à vinculatividade judicial; c) versar sobre a experiência portuguesa que, em decisão do Tribunal Constitucional, decidiu por extirpar por completo a vinculatividade judicial do ordenamento jurídico português; d) tratar sobre a vinculatividade judicial e a sua relação com o princípio da independência dos tribunais.

Na delimitação do tema levanta-se o seguinte problema: Qual é a melhor maneira de conectar a vinculatividade judicial com o princípio da independência dos tribunais?

Para o equacionamento do problema levanta-se a seguinte hipótese: a melhor forma de relacionar a vinculatividade judicial com o princípio da independência dos magistrados estabelece-se com o menor enrijecimento do sistema e, por consequência, com a maior liberdade criativa do magistrado.

As técnicas utilizadas neste estudo serão a pesquisa bibliográfica, a categoria e o conceito operacional, quando necessário. Outros instrumentos de pesquisa, além daqueles anteriormente mencionados, poderão ser acionados para que o aspecto formal deste estudo se torne esclarecedor ao leitor.

Para dar sustentação a este artigo buscou-se, também, o ensinamento de diversos autores que, por apresentarem percepções diferenciadas sobre o tema em estudo, auxiliaram na elucidação dos significados e contextos de determinadas categorias apresentadas nesta pesquisa.

\section{THE BINDING ELEMENT:}

\section{A Vinculatividade e sua Alocação nos Subsistemas que Compõem a Família Jurídica Ocidental}

Iniciando os trabalhos, versaremos sobre o binding element (o reconhecido efeito vinculativo) e sua alocação nos subsistemas que compõem a família jurídica ocidental. Para tanto, faremos uma análise das duas culturas jurídicas (common law e civil law), objetivando revelar a possível presença do efeito vinculativo em ambos os subsistemas.

A common law é um Direito original, radicado essencialmente na história e na tradição dos povos anglo-saxônicos (JERÓNIMO, 2015, p. 96). Ele foi criado na Inglaterra a partir do século 11 e posteriormente levado para as colônias britânicas, nas quais se manteve como matriz dos sistemas jurídicos locais mesmo depois da independência desses territórios. Hoje, engloba a generalidade dos países de língua inglesa - Reino Unido, Irlanda, Estados Unidos da América, Canadá, Austrália, Nova Zelândia, etc. (JERÓNIMO, 2015, p. 93).

Várias foram as evoluções deste subsistema ao longo da História, observando-se que as mais significativas - obviamente em solo inglês, por estarem ali suas raízes - ocorreram a partir das reformas judiciárias do século 19, marcando o início do que a doutrina designa por período moderno do Direito inglês, que dura até aos nossos dias (JERÓNIMO, 2015, p. 102-103). Entre as diversas alterações, destacam-se as que fazem referências às categorias e aos conceitos operacionais, posto que eles, na sua essência, fazem-nos compreender o modelo de produção e aplicação dos precedentes. ${ }^{1}$

\footnotetext{
Embora muitos considerem que, na tradição jurídica do common law, a única fonte do Direito é o precedente, tal pensamento evidencia-se equivocado, dado que a lei, quando efetivamente criada pelo Parlamento, possui posição hierarquicamente superior à própria jurisprudência. Em caso, portanto, de contradição entre um precedente jurisprudencial e uma determinada interpretação da norma legal, esta última prevalece. A par da jurisprudência e da lei, são igualmente reconhecidas como fontes do Direito, mas de maneira subsidiária, o costume e a doutrina (JERÓNIMO, 2015, p. 103).
} 
A doutrina do precedente vinculativo "[...] faz depender a força vinculativa dos precedentes da natureza do tribunal que profere a decisão e da relação hierárquica desse tribunal com outros tribunais que venham a pronunciar-se sobre casos semelhantes no futuro" (JERÓNIMO, 2015, p. 104). Assim, "quanto mais alto for o tribunal, maior será a força vinculativa do precedente fixado pelas suas decisões" (2015, p. 104). Esta concepção, portanto, tem por objetivo vincular as decisões prolatadas por tribunais de hierarquia superior aos casos semelhantes sub judice tratados pelos tribunais inferiores. A vinculação adrede ventilada, entretanto, tem relação direta com a identificação da ratio decidendi, ou seja, aquela que "[...] constitui a regra de Direito de aplicação obrigatória para casos futuros semelhantes" (p. 107). No sistema inglês, e isso também vale para os demais países que integram o subsistema anglo-saxônico, ao interpretarem as decisões anteriores sobre fatos semelhantes aos fatos sub judice, os juízes procuram distinguir o critério decisivo que estava na base da decisão anterior (denominado ratio decidendi) de outras considerações tecidas pelo tribunal a propósito do problema, mas não essenciais para a sua solução (denominadas obiter dictum), porque apenas estão obrigados a seguir o primeiro, não as segundas (JERÓNIMO, 2015, p. 108). Assim, o que, de fato, é relevante para a aplicação da doutrina do precedente vinculativo é a identificação da ratio decidendi, restando descartados, por sua vez, os argumentos obiter dictum, ou seja, aqueles que compõem a decisão, mas não são essenciais para solução do litígio. A partir da identificação da ratio decidendi, passa a ser possível verificar a plausível semelhança entre o precedente e o caso sub judice e, por conseguinte, perceber se, de fato, as razões daquele possuem total sintonia com este. Em caso positivo, aplica-se; caso contrário, rejeita-se. Neste último caso, é possível utilizar-se de duas técnicas: a) o distinguishing, reconhecida como a técnica das distinções, consistente no afastamento de um precedente vinculativo em virtude de sua inadequação (JERÓNIMO, 2015, p. 108); b) o overruling, que se trata da anulação do precedente vinculativo para aplicação de um novo, com sentido diferente.

Mais especificadamente quanto à vinculatividade dos precedentes, Teresa Arruda Alvim Wambier advoga que o que se entende é que, no sistema common law, o "[...] o juiz não pode desapontar ${ }^{2}$ os cidadãos" (WAMBIER, 2009, p. 124), ou seja, "[...] estes não podem ser surpreendidos por uma decisão que nunca poderia ter sido imaginada antes" (p. 124). Assim, segundo ela, a previsibilidade, neste sistema, é inerente ao Estado de Direito e, portanto, é parcela importantíssima e irrefutável para a manutenção do próprio sistema jurídico (p. 124). O pensamento da autora nos convida a concluir no sentido de que a vinculatividade dos precedentes, no sistema em questão, tem por fim afiançar a tão sonhada previsibilidade/segurança jurídica/ estabilidade/certeza. Ademais, é possível inferir que, segundo a autora, o binding element (o elemento que vincula) está, portanto, presente neste sistema por meio da doutrina do precedente vinculativo, objetivando, na sua essência, garantir a previsibilidade do sistema, nutrindo, assim, o grau de confiança dos cidadãos.

No mesmo sentido, mas com outro fundamento, Wambier aduz que a vinculatividade dos precedentes, neste sistema em tela, além da previsibilidade, é justificada pela necessidade de igualdade, que, segundo a autora, é "[...] atingida através da seleção de aspectos do caso que deve ser julgado, que devem ser considerados relevantes, para que esse caso seja considerado semelhante a outro, e decidido da mesma forma" (2009, p. 125). Consoante a autora, portanto, não somente a previsibilidade justifica a vinculatividade (o binding element), mas, ainda com mais força, a igualdade, direito de primeira monta, tendo em vista que ela possibilita dar a casos semelhantes uma mesma decisão. Com o exposto, é possível perceber que o que se demonstra é que não só se está a buscar uma igualdade formal, mas sim sua caracterização material ou substancial, uma vez que dar os mesmos fundamentos a fatos semelhantes não se está a aplicar ditames jurídicos distintos, o que, por si só, se assim tivesse se procedido, poderia desvelar uma injustiça indefensável.

Complementando o posicionamento de Wambier, Barroso e Mello consignam que, além da previsibilidade (segurança jurídica) e igualdade (isonomia), a eficiência também é elemento justificador para a adoção de um sistema de precedentes e, em consequência, para que entre em jogo, de maneira contundente, a vinculatividade judicial. Segundo os autores, "[...] o respeito aos precedentes possibilita que os recursos que dispõe o Judiciário sejam otimizados e utilizados de forma racional" (BARROSO; MELLO, 2016, p. 23). Estando os juízes obrigados a observar o entendimento dos Tribunais, estão eles, nas palavras dos autores, não consumindo seu tempo ou os recursos materiais de que dispõem para redecidir questões já apreciadas (BARROSO;

Itálico conforme o original. 
MELLO, 2016, p. 23-24). Sendo assim, constatamos que Wambier, Barroso e Mello, de modo bem rígido, possuem o entendimento de que a vinculatividade judicial é medida que se impõe no sistema jurídico como um todo, tendo em vista que tal postura auxilia na previsibilidade, na isonomia e, para Barroso e Mello, na eficiência do sistema. Sem esta vinculatividade judicial bem definida, o sistema fica propenso a arbitrariedades e ao "decisionismo".

Argumentando sobre o tema, Michele Taruffo (2014), já de uma maneira mais sutil do que adrede defenderam Wambier, Barroso e Mello, aduz que "[...] não é apropriado dizer que o precedente da common law é vinculante" (p. 7), tendo em vista que, segundo ele, mesmo no sistema inglês, que aparenta que o precedente é dotado de maior eficácia, "[...] os juízes usam numerosas e sofisticadas técnicas argumentativas, entre as quais o distinguishing e o overruling a fim de não se considerarem vinculados ao precedente que não pretendem seguir" (p. 7-8). Permanece, contudo, verdadeiro, consoante o autor, que naquele ordenamento, de fato, o precedente é dotado de uma força considerável, "[...] mas esta força é sempre reversível, revogável, anulável, defeasible" (p. 8). Arremata apondo que, no sistema americano, a força do precedente existe, mas em um menor grau, uma vez que "[...] os juízes americanos aplicam os precedentes com grande discricionariedade, isto é - por assim dizer - quando não encontram razões suficientes para não o fazer" (TARUFFO, 2014, p. 8). No mesmo sentido, Sodero sustenta que o precedente nunca pode ter uma retitude absoluta, tendo em vista, segundo ele, "[...] la inabarcable variedad y el continuo cambio de las relaciones de la vida ponen constantemente al que aplica las normas ante nuevas cuestiones" (SODERO, 2004, p. 227). E mais, consagra que não só está facultado ao juiz, mas inclusive é seu dever, afastar-se do precedente que contém uma interpretação incorreta ou um desenvolvimento do Direito não suficientemente fundamentado ou, ainda, se a questão retamente já decidida num precedente resulta para seu tempo não mais concebível para ser reaplicada (SODERO, 2004, p. 228).

Do mesmo modo que os autores anteriores, Marco Croce, após abordar extensivamente o tema, aduz que a doutrina inglesa do stare decisis, que defende o precedente vinculativo, "[...] non presenta quelle rigidittà estreme che l'immaginario giuridico coletivo vorrebbe attribuirle" (CROCE, 2006, p. 1.120). E ainda aponta que, no sistema estadunidense, a regra do stare decisis sempre foi aplicada com muita flexibilidade. Segundo o autor, "[...] sin dagli albori, a causa dela necessità di adattare la common law inglese alle diverse esigenze dele nuove ed eterogenee comunità americane, le corti superiori e, especialmente, la Corte Suprema Federale trattarono il problema con maggiore elasticità" (p. 1.120-1.121).

A partir do exposto anteriormente, chegamos à seguinte conclusão acerca da vinculatividade judicial no sistema common law: a) embora consideremos interessante o posicionamento de Wambier, Barroso e Mello de entender que a previsibilidade, a isonomia e, para os últimos dois, a eficiência são elementos justificadores para adesão do sistema de precedentes, acreditamos que tal postura não tem assertividade, tendo em vista que a complexidade que compõe o Direito pós-moderno impede que qualquer postura rígida seja tomada a fim de enrilhar o sistema. Preocupa-nos o fato de que ao defender um sistema austero de precedentes, está-se permitindo que os julgadores, em virtude da obrigatoriedade que emana do modelo e com o fim de manter a higidez do ordenamento, analisem cegamente os julgamentos (sem qualquer juízo de valor e discricionariedade), proporcionando, obviamente, soluções injustas. O ideal seria que um sistema de precedentes pudesse, de fato, traduzir valores de segurança, isonomia e eficiência, mas isso, na prática, tende a constituir uma incisiva falácia; b) em virtude do que exibimos anteriormente, cremos que os precedentes no sistema common law devem ser compreendidos, justamente em virtude da complexidade dos casos e com o fim de conservar a independência e o juízo de valor do magistrado (entende-se discricionariedade), como aponta Taruffo, com uma força considerável, mas não fundamentalmente obrigatória. Isto nos faz concluir, já num primeiro momento, que as técnicas do distinguishing e do overruling foram justamente erigidas no sistema common law para proteger a independência dos magistrados, pois aquelas permitem que estes, quando em posição incerta quanto à aplicabilidade do precedente, afastem-no por livre escolha e de maneira fundamentada; c) em suma, a vinculatividade no sistema common law encontra-se presente substancialmente nos precedentes, entretanto estes, diferentemente do que muitos acabam por acreditar, devem ser considerados tão somente como pertencentes de uma força considerável (não necessariamente compulsória).

Passemos agora para o subsistema da civil law. Este sistema engloba, segundo Patrícia Jerónimo, a maioria dos países da Europa Ocidental, e, desde o fim da guerra fria, também a generalidade dos países da Europa Oriental. Características deste sistema, outrossim, estão presentes nos territórios colonizados pelos 
países europeus a partir do século 16 - países africanos, asiáticos e latino-americanos, no Estado da Louisiana (EUA) e no Canadá francês - e em países como a Turquia e a Etiópia, que, em virtude da sua não colonização, adotaram modelos dos códigos europeus para sua rápida modernização (JERÓNIMO, 2015, p. 67). O Direito Romano constitui a matriz fundadora deste subsistema, podendo-se afirmar que os países que o integram são todos aqueles que receberam, portanto, os respectivos sistemas jurídicos do Direito Romano compilado (2015, p. 68). Quanto à sua fonte precípua, embora haja diferenças de pormenor, é possível destacar que, neste subsistema, "[...] todos dão primazia à lei" (p. 70). A lei, destarte, "[...] é simultaneamente o modo normal de criação de normas jurídicas e a fonte hierarquicamente superior, que sempre prevalecerá em caso de contradição entre as suas disposições e o disposto por alguma das demais fontes de Direito" (p. 71). O precedente, por sua vez, possui função, ao menos primacialmente, de fonte jurídica mediata (p. 69). Outras fontes típicas são admitidas: o costume (p. 71-72) e a doutrina (p. 80).

Adentrando na seara da vinculatividade, consigna-se de que há uma certa tendência de conectar o binding element apenas aos precedentes, posto que costumeiramente, no sistema da civil law, fala-se muito do efeito vinculativo de certos institutos derivados das decisões dos tribunais. Tal postura epistemológica, entretanto, é equivocada, uma vez que, antes de mais nada, o que, de fato, pode ser considerar com caráter vinculativo, no sistema romano-germânico, é a lei. É esta, portanto, a fonte que tem caráter vinculativo no sistema da civil law, haja vista que ela é traduzida como fonte jurídica precípua e de maior legitimidade teórico-prática. Neste sentido é o pensamento de Miguel Reale, que aponta que o Direito em vigor nas nações latinas e latino-americanas, bem como na restante Europa continental, "[...] funda-se, primordialmente, em enunciados normativos elaborados através de órgãos legislativos próprios" (REALE, 2004, p. 142). Embora, contudo, seja esta a postura inicial e que realmente qualifica o subsistema em tela, segundo Wambier, esta vinculatividade da lei tem sido suavizada ao passar dos tempos por algumas técnicas empregadas na redação das leis, consistentes "[...] na inclusão de conceitos tidos como vagos, indeterminados ou abertos e de cláusulas gerais" (WAMBIER, 2009, p. 128).

Leonardo Estevam de Assis Zanini, ao tratar sobre este abrandamento perpetrado na vinculatividade legal, argumenta que isto é fruto da aceleração da mutabilidade dos valores e da complexidade da realidade social (ZANINI, 2008, p. 39). Em virtude destes fatos que, segundo o autor, está-se a migrar de um sistema fechado, aquele no qual o juiz estava preso à letra da lei, para um sistema relativamente aberto, ou seja, "[...] aquele em que há um grande número de normas em estado fluido e contínua transformação; é aquele em que é atribuída ao jurista a tarefa de colaborar com o legislador e com o juiz no trabalho de criação do novo direito" (ZANINI, 2008, p. 40). Arremata o autor, a posteriori, afirmando que, neste novo sistema "[...] as hipóteses legais são formuladas em termos intencionalmente imprecisos e indeterminados, permitindo maior mobilidade do juiz em cada caso, mas não apenas maior mobilidade: é preciso também a possibilidade de buscar a precisão e a determinação requeridas em conceitos extrajurídicos" (p. 40). Ele está, portanto, a defender a ideia de uma interdisciplinaridade e, outrossim, de uma abertura no campo de visão do jurista que, a nosso ver, nada melhor expressa a acepção global do Direito que, em virtude da atual situação do Direito pós-moderno, permite que as soluções jurídicas sejam tomadas levando, de fato, em consideração a realidade circundante (num verdadeiro Direito como experiência, como defende Reale (2002, p. 165).

Um conceito vago, indeterminado ou aberto é considerado, em si mesmo, "[...] uma técnica extremamente operativa, porque capacita o juiz a tomar sua decisão mais rente aos casos concretos, bem como proporciona uma duração maior ao texto da lei" (WAMBIER, 2009, p. 129). É o caso, por exemplo, segundo Wambier, da análise da expressão baixa renda para a concessão de um determinado benefício previdenciário ( $p$. 129). Já a cláusula geral, por sua vez, consiste numa "[...] expressão linguística em que há conceitos vagos e que, além disso, incorpora em si mesma, princípios jurídicos" (2009, p. 129). Um bom exemplo, segundo a autora, é da expressão função social da propriedade, a qual retira desta o caráter de direito absoluto e, em contraposição, apoia que tal direito deve ser exercido em conformidade com o bem geral da sociedade ( $p$. 129). Tais técnicas, como se percebe, permitem deveras ao juiz criar o Direito, formulando regras para o caso concreto, ou seja, possibilita ao intérprete que ele utilize de sua criatividade para resolução dos casos concre- 
tos. Esta criatividade, entretanto, só deveria ser externada nos hard cases $^{3} \mathrm{e}$, ainda com mais vigor, nos casos trágicos (ATIENZA, 2014, p. 273), pois o manuseio de tal alternativa nos casos ditos fáceis compromete o Estado de Direito (WAMBIER, 2009, p. 130). Há que, portanto, segundo Wambier, haver limites nesta criatividade, justamente para que se possa respeitar a previsibilidade, a estabilidade e a certeza do sistema (que também são, ou deveriam ser, peças-chaves do sistema romano-germânico).

Além das técnicas anteriormente apresentadas, Wambier ainda aponta a inclusão dos princípios jurídicos como uma forma mitigadora da vinculatividade da lei. Os princípios jurídicos, segundo a autora, "[...] são normas jurídicas, formuladas intencionalmente de uma maneira vaga, com marcante dimensão axiológica" (WAMBIER, 2009, p. 131). Exemplificando, Wambier aponta o caso de uma decisão em que se considerou que a avó não poderia ser proibida de visitar os netos, pelo seu filho e pela sua nora ("[...] só razões muito sérias poderiam levar a esta proibição, sob pena de estar diante de um abuso do pátrio poder") (p. 131). Da mesma forma que os conceitos vagos e as cláusulas gerais, os princípios também estimulam a criatividade do magistrado, bem como, interpretados arbitrariamente, podem ferir, da mesma forma, a previsibilidade, a estabilidade e a certeza do sistema.

Algumas questões precisam ser discutidas antes de continuarmos nossa dilação: a) a adoção de conceitos indeterminados, cláusulas gerais e princípios jurídicos, de fato, mitigaram a força da vinculatividade legal no sistema romano-germânico. Isto, contudo, não significa concluir, valendo-se dos ensinamentos de Eros Grau (2011, p. 206-207), que tal abertura dos textos de Direito tenha aberto caminho para o juiz atribuir a tais vazios interpretativos juízos de oportunidade, ou seja, juízos discricionários que afastam um verdadeiro juízo de legalidade. Este deve ser incorporado pelo juiz, no trato com tais institutos de textura aberta, justamente para preservar o sistema e, assim, mantê-lo virtuosamente íntegro (SOLUM, 2009, p. 16). Somente assim tais institutos podem ser incorporados, impedindo a subversão da ordem jurídica e, por consequência, afastando qualquer postura solipsista dos magistrados; b) a interpretação dos institutos abertos a ser realizada pelos magistrados, embora baseada num juízo de legalidade, justamente para impedir subjetividades indesejadas, não deve ser compreendida, contudo, de maneira estanque, cerrada e/ou amarrada, na forma, portanto, de um sistema fechado, uma vez que tal atitude evitaria o bom funcionamento do sistema jurídico. A independência dos magistrados, neste contexto, deve ser preservada, tendo em vista que não cabe a ninguém, nem mesmo ao sistema, impedir a determinado juiz que este interprete da maneira que achar melhor, desde que não se olvide de agir de maneira sábia (na teoria e na prática), sensata e respeitando a integridade do sistema na sua plenitude (NAVARRO, 2019, p . 6).

Essa mitigação do poder de vinculatividade legal adrede exposta fez exsurgir uma concepção diferenciada da atividade judicial, dado que permitiu aos juízes, por meio dos conceitos ditos abertos, das cláusulas gerais e dos princípios, valerem-se, por autorização da lei, de uma criatividade mais alargada, ou seja, de uma percepção imaginativa mais condizente com a nova realidade carreada pelo Direito pós-moderno. $E$ isso, paulatinamente e por consequência, acabou por abrir espaço para que a força argumentativa oriunda da atividade judicial fosse levada em conta, harmonicamente com a lei, para a efetiva tomada de decisão judicial. Tomaram lugar, portanto, a partir deste precípuo esforço de instituir a criatividade judicial, os precedentes nos sistemas romano-germânicos.

Os precedentes, contudo, não adentraram abruptamente no subsistema da civil law já aderindo uma força vinculativa, ou seja, já partilhando em igualdades de condições com a vinculatividade legal. Eles, na verdade, foram ganhando espaço, argumentativamente, de maneira meramente persuasiva. Patrícia Jerônimo, neste contexto, afirma, enfaticamente e de maneira geral, que os precedentes, nos países que integram o subsistema romano-germânico, valem apenas como precedente persuasivo, diferentemente do que ocorre na common law (JERÓNIMO, 2015, p. 75). Do mesmo modo, Mariana Capela Lombardi Moreto advoga que, no sistema de civil law, o precedente judicial "[...] interpreta em geral papel de cunho persuasivo, de valor moral (persuasive authority)" (2012, p. 8). Taruffo, outrossim, sedimentando tal postura, consigna que, nos ordena-

Cfr. WAMBIER (2009). Estabilidade e adaptabilidade como objetivos do direito: civil law e common law. p. 130: "[...] nos sistemas de common law, são, principalmente, cases of first impression, ou seja, a respeito dos quais não há precedentes. Mas são também aqueles mais complexos, em que o juiz faz escolhas". 
mentos de civil law, "[...] o grau de força que vem atribuído ao precedente é, provavelmente, menor do que aquele atribuído ao precedente da common law, mas nada exclui que existam precedentes tão influentes e persuasivos a ponto de serem impostos aos juízes sucessivos" (TARUFFO, 2014, p. 8).

Ao passar do tempo, contudo, segundo Wambier, instalou-se a necessidade, nos sistemas romano-germânicos, de se avaliar a possível conexão do princípio da igualdade com esta força atribuída aos precedentes, bem como se começou a questionar o papel do próprio Judiciário na construção do Direito. Para que seja preservado o princípio da igualdade, "[...] é necessário que haja uma mesma pauta de conduta para todos os jurisdicionados" (WAMBIER, 2009, p. 131). E mais, começou a se defender a necessidade de que a jurisprudência firmada passasse a ser respeitada (2009, p. 131). Ao que parece, o legislador já se deu conta dessas necessidades, ${ }^{4}$ tanto é que não só introduziu parâmetros flexíveis na lei, como, igualmente, tem decidido por incluir mecanismos que, enfaticamente, estão servindo não apenas para tratar os precedentes como meros argumentos persuasivos, mas sim defini-los gradativamente de maneira vinculativa (aproximando-se cada vez mais do modelo de precedentes vinculativos da common law). Como forma de demonstrar a inclusão destes mecanismos, trataremos a seguir da experiência brasileira que, paulatinamente, tem introduzido e, consequentemente, "commonlizado" (STRECK, 2013) o sistema romano-germânico.

\section{A VINCULATIVIDADE JUDICIAL À BRASILEIRA}

Para versar sobre o desenvolvimento da vinculatividade judicial no ordenamento jurídico brasileiro, valer-nos-emos de duas abordagens que, conjuntamente, auxiliarão na compreensão de nossa linha argumentativa. A primeira abordagem será a conceitual, na qual trataremos sobre as modalidades de eficácia dos precedentes, e a segunda será a normativa, quando versaremos sobre a evolução jurídica e seus contributos para a mudança de posicionamento na eficácia dos precedentes.

Passemos à abordagem conceitual. Segundo Luiz Roberto Barroso e Patrícia Perrone Campos Mello, os precedentes judiciais, no Direito brasileiro, produzem três espécies de eficácia: a) eficácia meramente persuasiva - os julgados com essa eficácia "[...] produzem efeitos restritos às partes e aos feitos em que são afirmados, são relevantes para a interpretação do Direito, para argumentação e para o convencimento dos magistrados" (BARROSO; MELLO, 2016, p. 19), contudo não geram qualquer efeito vinculante. São considerados meras fontes mediatas ou secundárias do Direito (p. 19); b) eficácia normativa em sentido forte - corresponde aos julgados e entendimentos que "[...] devem ser obrigatoriamente observados pelas demais instâncias e cujo desrespeito enseja reclamação" (BARROSO; MELLO, 2016, p. 20). Neste caso, portanto, os julgados possuem efeito vinculativo; c) eficácia intermediária - esta terceira categoria é residual e abriga, por isso, "[...] decisões judiciais com eficácia heterogênea que produzem efeitos impositivos em diferentes graus". Esta modalidade, portanto, encontra-se entre as duas primeiras, pois nem é meramente persuasiva, nem traduz, em partes, uma obrigatoriedade. ${ }^{5}$

Após esta análise conceitual, partimos para uma abordagem normativa. O processo de valorização da jurisprudência no Brasil pode ser compreendido, segundo Barroso e Mello, em três perspectivas ou etapas: a) o avanço do controle concentrado de constitucionalidade; b) a valorização da jurisprudência no Código de Processo Civil de 1973; c) a criação de um novo sistema de precedentes vinculantes no Novo Código de Processo Civil de 2015 (BARROSO; MELLO, 2016, p. 14). O controle concentrado de constitucionalidade, de inspiração europeia, é aquele que "[...] confere ao Supremo Tribunal Federal a competência para processar e julgar ações diretas" (BARROSO; MELLO, 2016, p. 15), que tenham como objetivo a "[...] a aferição da (in)constitucionalidade da norma, em tese, perante a Constituição Federal" (p. 15). É aquele controle, portanto, que

\footnotetext{
${ }^{4}$ Cfr. WAMBIER (2009). Estabilidade e adaptabilidade como objetivos do Direito: civil law e common law. p. 132: "[...] Não é saudável que convivamos eternamente com tribunais decidindo concomitantemente, de forma diferente, a mesma questão. Assim como não é conveniente que nossos tribunais sejam tribunais de 'grandes viradas'".

5 Cfr. BARROSO, Luís Roberto; MELLO, Patrícia Perrone Campos. Trabalhando com uma nova lógica: A ascensão dos precedentes no direito brasileiro. p. 20: “[...] Não são dotados de eficácia meramente persuasiva porque o próprio ordenamento lhes atribui efeitos para além dos casos em que foram produzidos, em favor ou desfavor de quem não era parte nestes, ou, ainda, porque o próprio direito determina expressamente que a observância dos entendimentos proferidos em tais julgados é obrigatória. Não é possível, por outro lado, afirmar que tais precedentes produzem eficácia normativa em sentido forte porque a lei não permite o uso de reclamação, em caso de desrespeito à orientação neles traçada".
} 
analisa a (in)constitucionalidade não incidentalmente num processo (esse é o controle difuso), mas sim abstratamente por meio de um processo que objetiva tratar apenas deste ponto. Com base nas lições de Barroso e Mello, reporta-se que a Constituição de 1988, tendo em vista que esta modalidade de controle já existia no Brasil mesmo que em curta escala, potencializou o uso das ações diretas com inovações que compreenderam: a) maior autonomia ao procurador-geral da República; b) ampliação do elenco de órgãos e entidades com legitimação para proporem ações diretas; c) ampliação dos instrumentos de deflagração de controle concentrado, com a inclusão da Ação Direta de Inconstitucionalidade (ADI), da Ação Direta de Inconstitucionalidade por Omissão (ADO) e da Arguição de Descumprimento de Preceito Fundamental (ADPF) e, com a aprovação da Emenda Constitucional n. 3/1993, da Ação Declaratória de Constitucionalidade (ADC) (BARROSO; MELLO, 2016, p. 15). Na sequência, a lei 9.868/99 regulamentou a ADI, ADO e ADC, explicitando que as decisões proferidas nestas ações produziriam efeitos vinculantes e gerais em relação aos órgãos judiciais e à administração pública (BARROSO; MELLO, 2016, p. 15-16) e, da mesma forma posteriormente, a lei 9.882/99 regulamentou a ADPF (2016, p. 16). Por fim, ainda dentro do controle concentrado, a Emenda Constitucional 45/2004 estabeleceu a possibilidade de edição de súmula vinculante, pelo Supremo Tribunal Federal, que "[...] refletisse o entendimento defendido pelo Supremo em reiteradas decisões sobre matéria constitucional, tornando sua observância obrigatória para o Judiciário e para a administração pública" (BARROSO; MELLO, 2016, p. 16). Conforme é possível verificar, o controle concentrado de constitucionalidade, após o advento da Constituição de 1988, passou por evoluções que se traduziram numa supervalorização da jurisprudência e, conjuntamente, da vinculatividade judicial, uma vez que as decisões prolatadas nesta modalidade de controle introduziram o binding element como um de seus elementos obrigatórios. Assim, seja por meio das decisões das ações diretas ou da cristalização de posicionamento das súmulas vinculantes, a eficácia de tais precedentes é genuinamente normativa. Neste primeiro ponto, portanto, já é possível antever a importância da vinculatividade do precedente no Direito brasileiro, bem como aferir que o propósito do constituinte era defender a previsibilidade e estabilidade do sistema.

Paralelamente ao descrito anteriormente, o Código de Processo Civil de 1973 "[...] vinha sendo objeto de uma série de alterações pontuais ${ }^{6}$ que conferiam maior eficácia à jurisprudência consolidada nos tribunais". A lei 9.756/98 autorizou o relator a inadmitir, monocraticamente, recursos em confronto com súmulas ou com a jurisprudência consolidada nos Tribunais Superiores, ou que desse provimento aos apelos compatíveis com tais precedentes; ${ }^{7}$ e estabeleceu a desnecessidade de submissão da arguição incidental de inconstitucionalidade de uma norma ao plenário dos Tribunais, quando já houver pronunciamento destes ou do plenário do Supremo Tribunal Federal sobre a questão. ${ }^{8} E$ da normatização de tais dispositivos que exsurge a vinculatividade judicial no CPC/1973. Na sequência, a lei 10.352/2001 dispensou o duplo grau obrigatório de jurisdição em decisão contra a Fazenda Pública que estivesse em consonância com jurisprudência do plenário do STF ou com súmula deste ou do Tribunal Superior competente. ${ }^{9}$ A lei 11.232/2005 criou os embargos desconstitutivos da coisa julgada incompatível com a Constituição à luz da jurisprudência do STF. ${ }^{10} \mathrm{Em} \mathrm{2006}$, a lei 11.418 regulamentou a exigência, originada pela Emenda Constitucional 45/2004, de repercussão geral como requisito necessário para o conhecimento do recurso extraordinário e determinou que tal requisito estaria presente quando o acórdão contrariasse súmulas ou entendimentos consolidados na Corte Constitucional. ${ }^{11}$ Essa mesma lei criou um procedimento especial para o julgamento de recursos extraordinários repetitivos, que previa que a orientação firmada pela Corte Constitucional sobre o mérito da questão, em um caso de paradigma, abriria para o Tribunal de origem a possibilidade de declarar prejudicados apelos idênticos. ${ }^{12}$ Posteriormente, o procedimento especial para julgamento de recursos repetitivos foi replicado para os recursos especiais apreciados pelo Superior Tribunal de Justiça e para os recursos de revistas julgados no Tribunal Su-

\footnotetext{
6 Estas alterações são versadas ponto a ponto por Barroso e Mello In BARROSO, Luís Roberto; MELLO, Patrícia Perrone Campos. Trabalhando com uma nova lógica: A ascensão dos precedentes no direito brasileiro. p. 16-17.

Cfr. Artigo 544, §3o, do CPC/1973 (redação atribuída pela Lei 9.756/98).

8 Cfr. Artigo 481, parágrafo único, do CPC/1973 (redação atribuída pela Lei 9.756/98).

9 Cfr. Artigo 475, §3으, do CPC/1973(redação atribuída pela Lei 10.352/2001).

${ }^{10}$ Cfr. Artigo 475-L, inciso II e §1ํ, CPC e artigo 741, parágrafo único, CPC (redação atribuída pela Lei 11.232/2005).

${ }^{11}$ Cfr. Artigo 543-A, §3ㅇ, CPC (redação atribuída pela Lei 11.418/2006).

${ }^{12}$ Cfr. Artigo 543-B, §3ํ, CPC (redação atribuída pela Lei 11.418/2006).
} 
perior do Trabalho, por meio da Lei no $11.672 / 2008^{13}$ e da Lei 13.015/2014, ${ }^{14}$ respectivamente. Após Barroso e Mello versarem ponto a ponto sobre as referidas inovações legislativas, concluem que estas indicavam, de fato, "[...] uma persistente inclinação a atribuir às decisões judiciais efeitos para além do caso específico, bem como uma tendência a conferir efeitos expansivos também aos precedentes oriundos do controle difuso da constitucionalidade" (BARROSO; MELLO, 2016, p. 18).

Trataremos agora da eficácia dos precedentes no CPC/1973, como forma de demonstrar a evolução da vinculatividade judicial. As decisões proferidas pelos juízos de primeiro grau e pelos tribunais produziam eficácia meramente persuasiva. ${ }^{15}$ Por outro lado, as súmulas vinculantes e os acórdãos proferidos em controle concentrado eram dotados de eficácia normativa (BARROSO; MELLO, 2016, p. 21). Por derradeiro, a jurisprudência consolidada nos Tribunais, as súmulas simples e as decisões do pleno dos Tribunais que declarassem a inconstitucionalidade de uma norma eram dotadas de eficácia intermediária (p. 21). Até mesmo as decisões proferidas em repercussão geral e em recurso extraordinário repetitivo eram dotadas de uma eficácia intermediária, mesmo que com nível de obrigatoriedade distinto das anteriores (p. 21). Do exposto, é possível captar, da mesma forma que Barroso e Mello, que os precedentes dotados de efeitos normativos fortes eram raros no CPC/1973 (2016, p. 22), posto que, com é possível perceber, era a eficácia intermediária que possuía maior terreno. Não há como ignorar, contudo, a introdução gradual da vinculatividade judicial no ordenamento jurídico brasileiro oriundo das inovações legislativas do CPC/1973, uma vez que estas, paulatinamente, permitiram o enaltecimento das bases epistemológicas do sistema de precedentes na pragmática jurídica, e, concomitantemente, almejaram preservar a previsibilidade, estabilidade e certeza do sistema jurídico, corolários cruciais defendidos pela cultura romano-germânica.

A trajetória apontada anteriormente completou-se com o Novo Código de Processo Civil de 2015 que, no artigo 927, definiu os entendimentos a serem obrigatoriamente observados pelas demais instâncias (isso em relação a decisões de Tribunais superiores): a) as súmulas vinculantes, b) as decisões proferidas pelo STF em sede de controle concentrado de constitucionalidade; c) os acórdãos proferidos em julgamento com repercussão geral ou em recurso extraordinário ou especial repetitivo; d) os julgados dos Tribunais proferidos em incidente de resolução de demanda repetitiva; e) em incidente de assunção de competência; f) os enunciados da súmula simples da jurisprudência do STF e do STJ e g) as orientações firmadas pelo plenário ou pelos órgãos especiais das Cortes de segundo grau (BARROSO; MELLO, 2016, p. 18). Como forma de manutenção deste estado de obrigatoriedade, o artigo 988 do mesmo Código previu a possibilidade de ajuizamento de reclamação para cassar decisões divergentes de todos os entendimentos e precedentes indicados pelo artigo 927, ressalvadas apenas as hipóteses de descumprimento de súmulas simples e de orientações firmadas pelo pleno e pelos órgãos especiais dos tribunais (BARROSO; MELLO, 2016, p. 19). Passemos a tratar sobre a eficácia dos precedentes. São dotados de eficácia persuasiva as decisões proferidas pelos juízos de primeiro grau e os acórdãos dos Tribunais que não sejam proferidos em incidente de resolução de demanda repetitiva ou em incidente de assunção de competência (BARROSO; MELLO, 2016, p. 22). São dotados de eficácia normativa em sentido forte: as súmulas vinculantes, os julgados produzidos em controle concentrado da constitucionalidade, os acórdãos proferidos em julgamento com repercussão geral ou em recurso extraordinário ou especial repetitivo, as orientações oriundas do julgamento de incidente de resolução de demanda repetitiva e de incidente de assunção de competência (BARROSO; MELLO, 2016, p. 22). Produzem eficácia intermediária os enunciados da súmula simples da jurisprudência do STF e do STJ sobre matéria constitucional e infraconstitucional, respectivamente, e as orientações firmadas pelo plenário ou pelos órgãos especiais das cortes (p. 2223). Nota-se, a partir do revelado, que a vinculatividade judicial acabou por ser introduzida de maneira mais ativa no CPC/2015, haja vista que se vê uma maior presença de precedentes com eficácia normativa forte na análise detida do ordenamento jurídico. Ademais, é possível observar que o legislador quis, efetivamente, dar proteção à estabilidade e à previsibilidade do sistema, bem como prezar pela igualdade dos jurisdicionados, utilizando-se, para tanto, das bases epistemológicas do sistema de precedentes de origem inglesa, o que fez objetivando trazer legitimidade à sistematização. Este argumento é possível se confirmar no artigo 489, §1으,

\footnotetext{
${ }_{13}$ Cfr. Artigo 543-C, CPC (redação atribuída pela Lei 11.672/2008).

${ }^{14}$ Cfr. Artigo 896-B e 896-C, da Consolidação das Leis Trabalhistas (redação atribuída pela Lei 13.015/2014).

${ }^{15}$ Cfr. BARROSO, Luís Roberto; MELLO, Patrícia Perrone Campos. Trabalhando com uma nova lógica: A ascensão dos precedentes no direito brasileiro. p. 21.
} 
incisos V e VI, que trata sobre causas de rejeição de fundamentação para qualquer decisão judicial: a) o inciso $V$ aduz que não se considera fundamentada a decisão se ela se limitar a invocar precedente ou enunciado de súmula, sem identificar seus fundamentos determinantes nem demonstrar que o caso sob julgamento se ajusta àqueles fundamentos. ${ }^{16}$ Neste caso, portanto, depreende-se que a intenção do legislador era introduzir a expertise da identificação da ratio decidendi, que é requisito essencial no sistema anglo-saxônico a todos os casos que tenham por fim aplicar um precedente ou súmula, impedindo, assim, o magistrado de julgar com base puramente no texto da ementa de tais institutos. Constata-se, portanto, que o novo Código de Processo Civil, mais do que já se evidenciava no CPC/1973, efetivamente, transplantou, ao menos com rigor técnico, a doutrina do precedente vinculativo; b) o inciso VI aponta que também não será considerada fundamentada a decisão que deixar de seguir enunciado de súmula, jurisprudência ou precedente invocado pela parte, sem demonstrar a existência de distinção no caso em julgamento ou a superação do entendimento. ${ }^{17}$ Da mesma forma que no inciso anterior, há aqui uma inserção de técnicas oriundas do sistema anglo-saxônico: o distinguishing (sem demonstrar a existência de distinção) e o overruling (a superação do entendimento). Este inciso, conjuntamente com o anterior e com o que adrede fora exposto sobre o Novo Código de Processo Civil de 2015, confirma o fato de que a supervalorização dos precedentes não é mais apenas uma hipótese no ordenamento jurídico brasileiro, mas sim, com a nova regulamentação, passou a ser uma efetiva solução para os problemas sociais, associada, obviamente, com as demais fontes jurídicas. Assim, o que, com efeito, pretendia o legislador, e vem se confirmando com o texto normativo, era dar ainda maior ênfase à vinculatividade judicial, objetivando concretizar a previsibilidade, a estabilidade e a certeza do sistema e, paralelamente, carrear igualdade de soluções a todos os jurisdicionados (sem contar a eficiência que este sistema de precedentes vinculativos aparentemente propicia) (BARROSO; MELLO, 2016, p. 23).

\section{A EXPERIÊNCIA PORTUGUESA DOS ASSENTOS: Rumo à Vinculatividade Judicial Mitigada}

Após apresentar a real situação da vinculatividade em ambos os subsistemas que compõem a família jurídica ocidental, inclusive abordando o caso brasileiro, versaremos, neste penúltimo ponto, sobre a experiência portuguesa que, numa decisão de seu Tribunal Constitucional, expurgou o instituto dos assentos e, por consequência, seu caráter vinculativo do ordenamento jurídico. Trataremos o tema em dois momentos: em um, explanaremos sobre a decisão em questão, apresentando os fundamentos que serviram de base para solução do caso; em outro, dissertaremos sobre o panorama que se instalou no ordenamento jurídico português após a decisão do Tribunal Constitucional, dando ênfase a possível vinculatividade dos precedentes.

Nas palavras de Maria Cristina da Silva Carmignani, no período de formação do Estado português, o costume era a fonte primordial do Direito, havendo, para tanto, costumes gerais e jurisprudenciais (CARMIGNANI, 2016, p. 19). Estes, contudo, sem desconsiderar a força daqueles, tinham uma presença mais marcante na sociedade portuguesa da época, haja vista que o Direito Judiciário era considerado, de fato, o caminho para as soluções mais sábias e coerentes. Isto é possível constatar, inclusive, na criação do que eles dominavam façanhas ("[...] decisões judiciais que adquiriam força vinculante") $(2016$, p. 20), uma vez que estas não só davam primazia à produção judicial, como também conferiam ao trabalho dos jurisconsultos observância obrigatória. Após o século 16, entretanto, o termo façanha cai em desuso, sucedendo-lhe expressões casos julgados e arestos, "[...] assim chamadas as decisões judiciais, não suscetíveis de reforma, proferidas em forma de julgamento definitivo, pelos tribunais superiores" (p. 21). Estas decisões, contudo, ganham novos contornos, quando, em 1518, Dom Manuel I expede um alvará conferindo aos desembargadores da Casa da Suplicação de Lisboa, a mais alta Corte Judiciária portuguesa da época, "[...] a resolução de dúvidas de interpretação que surgissem a respeito de algum preceito e a dita solução ficaria registrada no Livro dos Assentos, tendo força vinculante para casos futuros idênticos" (p. 22), o que fez exsurgir, portanto, estes institutos como jurisprudência obrigatória. Esta solução adotada no alvará de 1518, consoante Carmignani, foi repetida nas demais Ordenações reinóis (Manuelinas e Filipinas) (p. 22) e permaneceu assente até mesmo quando da promulgação do Código Civil Português (p. 27).

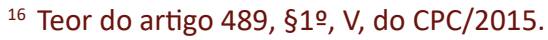

17 Teor do artigo 489, §1으, VI, do CPC/2015.
} 
O Direito Judiciário lusitano, contudo, na esteira do ideário da separação dos poderes no século 18 e com a edição do Código Civil de 1867, acaba perdendo força, em especial em virtude da primazia da lei (CARMIGNANI, 2016, p. 28) que, paulatinamente, passou a se firmar como fonte precípua não apenas em solo português, mas em todos os países pertencentes ao subsistema romano-germânico. O juiz, a partir de então, passa de solucionador efetivo dos problemas para um papel mecânico de aplicação da norma, compilada em códigos, o que vem corroborado pela técnica adotada pela escola da exegese (CARMIGNANI, 2016, p. 28). Bem verdade que a partir do século 19, gradativamente se verificou a necessidade de se estabelecer uma maior abertura ao ordenamento jurídico, aumentando, portanto, a atuação judicial. Isto, entretanto, não foi suficiente para se firmar um novo paradigma, permanecendo nos países da Europa continental a concepção de que a lei era e é, indubitavelmente, a fonte primordial do Direito (CARMIGNANI, 2016, p. 28). Daí a razão histórica do porquê os assentos começaram, paulatinamente, a perder força no Direito lusitano e, em consequência, foram integralmente banidos do ordenamento jurídico pelo Tribunal Constitucional no acórdão $\mathrm{n}$. 743/1996.

No julgamento do processo n. 240/94, o Tribunal Constitucional Português, já amparado em decisões anteriores proferidas em sede de fiscalização concreta de constitucionalidade (acórdãos 810/93, 407/94 e 410/94), declararam inconstitucional a norma constante do artigo 2 ㅇ do Código Civil vigente, ${ }^{18}$ na parte em que atribui aos Tribunais competência para fixar doutrina com força obrigatória geral, por violação do preceituado no artigo 115ㅇ, no 5, ${ }^{19}$ da Constituição da República Portuguesa. A partir de então, como se demonstrará, o instituto dos assentos foi expurgado do ordenamento jurídico português.

Conceituação. Segundo José Joaquim Gomes Canotilho, os assentos "[...] eram normas matéria "recompostas" através de uma decisão jurisdicional ditada pelo Supremo Tribunal de Justiça sempre que houvesse contradição de julgados sobre as mesmas questões de direito no domínio da mesma legislação" (2003, p. 938). Quanto à sua gênese, Alfredo Castanheira Neves elucidava que os assentos eram, deveras, constituídos como uma prescrição jurídica imperativa que se constituía no modo de uma norma geral e abstrata, que não só se impunha com força vinculativa normativa universal, mas sim se reconhecia legalmente com caráter de fonte de Direito (NEVES, 2014). Desde a sua instituição, em 1832, até a entrada em vigor do Decreto n. 12.353, de 22 de setembro de 1926, o Supremo Tribunal de Justiça não dispunha de competência para proferir assentos, mas tão somente para uniformizar a jurisprudência, mediante a interpretação e aplicação da lei nos casos concretos que lhe eram submetidos. ${ }^{20}$ Apesar de o Decreto n. 12.353 não atribuir a estes acórdãos de uniformização a designação de assentos, o Supremo Tribunal de Justiça assim passou a chamá-los a partir de dezembro de 1927. ${ }^{21}$ O Código de Processo Civil de 1939 consagrou a denominação de assentos aos acórdãos proferidos pelo pleno do Supremo Tribunal de Justiça, mantendo, contudo, o regime do Decreto n. 12.353; o Código de Processo Civil de 1961 eliminou a faculdade de alteração dos assentos pelo próprio Supremo Tribunal de Justiça; o Código Civil de 1967, em seu artigo 2ำ, veio, portanto, atribuir à doutrina fixada pelo assentos força obrigatória. ${ }^{22}$

Ainda na seara conceitual, aponta-se que os assentos, quando legítimos, podiam se instituir de duas maneiras: para fixar uma das várias interpretações possíveis da lei (assentos interpretativos), oportunidade na qual a norma visada passava a uma profunda recomposição, ou, outrossim, para preencher uma lacuna do sistema (assentos integrativos), criando, assim, a norma correspondente que depois se faria aplicar a um caso concreto. ${ }^{23}$

Fundamentação que acarretou na declaração de inconstitucionalidade. Propositalmente, apresentaremos os fundamentos que serviram de base para a declaração incidental de inconstitucionalidade dos assentos que restam traduzidos no Acórdão no 810/93, tendo em vista que é, com base nestes argumentos e no que

\footnotetext{
${ }_{18}$ Vide teor do artigo 2o: "nos casos declarados na lei, podem os tribunais fixar, por meio de assentos, doutrina com força obrigatória geral".

19 Vide teor do artigo 115으, no 5: "nenhuma lei pode criar outras categorias de actos legislativos ou conferir a actos de outra natureza o poder de, com eficácia externa, interpretar, integrar, modificar, suspender ou revogar qualquer dos seus preceitos".

20 Trecho do Acórdão no $743 / 96$

${ }^{21}$ Trecho do Acórdão no $743 / 96$

22 Trecho do Acórdão no 743/96

${ }^{23}$ Trecho do Acórdão no 743/96
} 
vem a se firmar nos arestos 407/94 e 410/94, que, em ato posterior, por meio do julgamento do Processo no 240/94, o Tribunal Constitucional, por definitivo, expurgou tal instituto do ordenamento jurídico. 1: O instituto em tela e seu procedimento ferem o princípio da tipicidade dos actos legislativos que, à época, encontrava-se estampado no artigo 115, no 5, da Constituição da República Portuguesa, sob a alegação de que as leis não podem autorizar que a sua própria interpretação, integração, modificação, suspensão ou revogação sejam afetadas por outro ato que não seja uma outra lei. Ademais, neste contexto, afastou-se a possibilidade de que a legitimidade de tal instituto pudesse se extrair da antiga norma do artigo 206, que, na sua essência, tratava sobre a publicidade de atos judiciais com força obrigatória; ${ }^{24} 2$ : 0 instituto dos assentos fere o princípio da independência dos tribunais, pois anquilosa e torna rígido o sistema, impedindo que os magistrados deem a solução ao caso que acharem mais adequada. Na sequência, consignam que seria recomendável, contudo, que se estabelecesse um procedimento de uniformização de jurisprudência, que, por óbvio, faria respeitar a previsibilidade e a igualdade dos jurisdicionados. Segundo eles, portanto, este novel procedimento, ao ser posto em prática, não atingiria a independência dos magistrados, mas tão somente possibilitaria que a jurisprudência qualificada seja firmada. ${ }^{25} \mathrm{~A}$ partir deste argumento, portanto, que o Tribunal Constitucional declarou inconstitucional a parte final do artigo 20 do Código Civil vigente à época.

A declaração de inconstitucionalidade dos assentos e a novel força dotada aos precedentes. A retirada dos assentos do ordenamento jurídico português instalou um novo cenário no que tange à força dos precedentes, que, a nosso ver, encontra-se consagrada numa vinculatividade judicial mitigada, posto que não mais se defende uma rigidez do sistema, nem sequer se está a desrespeitar a independência dos Tribunais, porém também não há como simplesmente considerar que os precedentes não mais detêm força alguma na construção do Direito Português. Na atualidade, o sistema jurídico português vê-se atrelado à força dos precedentes em três momentos: a) na fiscalização abstrata de constitucionalidade (artigo 281 da Constituição Portuguesa): neste caso a decisão proferida ostenta caráter geral e vinculante (denominado pelos portugueses de "força obrigatória geral") (STRÄTZ, 2016, p. 295); b) na fiscalização concreta de constitucionalidade (artigo 281, "3", da Constituição Portuguesa): neste caso, o Tribunal Constitucional avalia e declara, com força obrigatória geral, a inconstitucionalidade ou a ilegitimidade de qualquer norma, desde que o preceito normativo tenha sido julgado como inconstitucional ou ilegítimo em três casos concretos (SILVA, 2012, p. 413); c) no recurso de uniformização de jurisprudência (artigo 763 et seq.. do Código de Processo Civil): neste caso, as partes envolvidas no processo podem interpor recurso para o pleno das seç̧ões cíveis do Supremo Tribunal de Justiça no caso de o Supremo proferir acórdão que esteja em contradição com outro anteriormente proferido pelo mesmo Tribunal, no domínio da mesma legislação e sobre a mesma questão fundamental de Direito. Este recurso deve ser interposto no prazo de 30 dias a contar do trânsito da segunda decisão e, outrossim, não será admitido se a orientação perfilhada no acórdão recorrido estiver de acordo com jurisprudência uniformizada do Supremo Tribunal de Justiça. Segundo Paula Costa e Silva, contudo, esta uniformização da jurisprudência não deve ser compreendida no contexto de uma formação de precedentes vinculantes, dado que, segundo a autora, "[...] nel sistema portoghese non si può però attribuire un effeto di tale natura a questo tipo de decisioni" (SILVA, 2012, p. 421). Assim, o Tribunal inferior pode, de fato, assumir decisões contrastantes e a Suprema Corte pode mudar a própria orientação, ainda que tenha se consagrado em uma pronúncia de jurisprudência uniformizada (SILVA, 2012, p. 422). Está-se, portanto, diante da edificação de um precedente meramente persuasivo, que, mesmo que na prática acabe por contribuir para o enrijecimento do sistema, deve ser compreendido e defendido num viés substancialmente recomendatório. Em conclusão, constata-se que, no atual sistema português, a vinculatividade judicial encontra-se presente apenas na fiscalização abstrata e concreta de constitucionalidade (está após o julgamento dos 3 casos), já que, no caso do recurso de uniformização de jurisprudência, embora possa aparentar que seja composto de uma austeridade, não se aproxima nem de perto do antigo instituto dos assentos.

\footnotetext{
${ }^{24}$ Cfr. SILVA, Paula Costa e - L'uniformazione della giurisprudenza nel diritto portoghese. Rivista di diritto processuale, ano 68 , número 2 (2012). p. 412: "Tale decisione dichiarò, con forza vincolante erga omnes, l'incostituzionalità del suddetto istituto per violazione dell'artigo 115 della Costituzione portoghese, nel quale erano indicate le fonti del diritto. Agli assentos era stata infatti riconosciuta forza normativa dalla legge ordinaria, ma gli stessi assentos non erano inclusi nel catalogo delle fonti del diritto di cui all'artigo 115 della Costituzione".

${ }^{25}$ Trecho do Acórdão № 810/93
} 


\section{A VINCULATIVIDADE JUDICIAL E A INDEPENDÊNCIA DOS TRIBUNAIS}

Após tratarmos detidamente sobre a vinculatividade em ambos os subsistemas que compõem a família jurídica ocidental, inclusive valendo-nos das experiências brasileira e portuguesa, neste último ponto, de maneira sucinta, versaremos sobre tudo o que fora apresentado e, ao final, apontaremos qual acreditamos ser a melhor forma de relacionar a vinculatividade judicial com o princípio da independência dos magistrados.

Primeiramente, tratemos sobre a vinculatividade no sistema anglo-saxônico. Neste sistema, como já abordado anteriormente, a vinculatividade que se faz presente é a judicial, uma vez que, embora a lei tenha, de fato, primazia quando existente, é o precedente a fonte jurídica primária mais significante. Quanto à independência dos Tribunais, consignou-se, oportunamente, que esta não se faz plenamente mitigada, embora muitos considerem a força obrigatória dos precedentes neste subsistema, posto que estes, na realidade, são deveras reconhecidos com uma força tão somente considerável. As técnicas do distinguishing e o overruling auxiliam, neste diapasão, tendo em vista que elas permitem que o Direito se adéque à realidade circundante, bem como proporcionam saídas que permitem ao juiz manter sua independência funcional. Esta parece ser uma forma interessante de relacionar a vinculatividade judicial com a independência dos Tribunais, dado que é permitido ao juiz afastar um precedente ou até mesmo superá-lo quando, de fato, achar adequado e necessário. Ocorre, contudo, que, no caso do sistema romano-germânico, por questões históricas e culturais, isto acaba por não funcionar da mesma forma, embora se procedam transplantes constantemente, tendo em vista que estes, em virtude das codificações, acabam por enrijecer o sistema e/ou dar um indevido superpoder aos magistrados. Por este motivo, a nosso ver, esta é uma realidade que precisa ser depurada e introduzida com cautela num ordenamento jurídico codificado, pois, caso contrário, sua entrada abrupta pode, como se constata, trazer caminhos indesejados e soluções trágicas.

Passemos agora ao sistema romano-germânico. Trataremos, primeiramente, da realidade brasileira. Como se pôde constatar, do CPC/1973 ao CPC/2015 tivemos um efetivo transplante do modelo de precedentes vinculativos da common law, um aumento dos mecanismos que defendem uma força expressiva dos precedentes na criação do Direito e, por consequência, uma ainda maior presença da vinculatividade judicial. Diferentemente, contudo, do subsistema da common law, o modelo brasileiro, além de dotar ainda de uma maior força aos precedentes, também acaba por enrijecer o sistema com diversos mecanismos que, diferentemente do originário sistema inglês, põe amarras e desrespeita de forma contumaz o princípio da independência dos Tribunais (é o caso das súmulas vinculantes, por exemplo). Assim, o modelo brasileiro não conduz para uma boa relação entre a vinculatividade judicial e a independência dos Tribunais, uma vez que, além de transplantar por completo a doutrina dos precedentes vinculativos, acaba por restar composto de outros mecanismos que ferem e muito a criatividade e a percepção imaginativa do magistrado.

Por último, trataremos da realidade portuguesa. Conforme referimos anteriormente, a vinculatividade judicial presente nesta experiência jurídica é mitigada, tendo em vista que, tirando a força obrigatória geral presente na fiscalização abstrata e concreta de constitucionalidade, não há outros mecanismos que permitam no ordenamento jurídico lusitano reconhecer o precedente como obrigatório. Embora o recurso de uniformização de jurisprudência possa aparentar concluir que aí poderia se instar uma vinculatividade massiva, esta, contudo, não deve ser assim reconhecida, tendo em vista que, após a declaração da inconstitucionalidade dos assentos, não mais se permitiu no sistema português que outro instituto fosse estabelecido para trazer rigidez ao sistema. Por este motivo consideramos que a realidade portuguesa, de fato, aponta para a melhor relação entre a vinculatividade judicial e o princípio da independência dos Tribunais, pois não impede as percepções imaginativas, auxilia numa argumentação mais crítica e conduz, certamente, a decisões mais parcimoniosamente justas. Sem dúvida, o recurso de uniformização de jurisprudência faz-se necessário para que a jurisprudência qualificada mantenha-se vívida, conservada e detenha um espaço permanente, mas não pode ele servir para cegar a justiça que tanto necessita assentar-se alerta e com os olhos bem abertos. 


\section{CONCLUSÃO}

A pesquisa ora realizada tratou de identificar a melhor a relação entre a vinculatividade judicial e o princípio da independência dos Tribunais.

Inicialmente, abordou-se sobre a vinculatividade (the binding element) nos subsistemas anglo-saxônico e romano-germânico, dando ênfase a sua relação com a via judicial. Na sequência, versou-se sobre a vinculatividade nas realidades brasileira e portuguesa. Por fim, tratou-se sobre a vinculatividade judicial e a sua relação com o princípio da independência dos Tribunais.

Com a pesquisa realizada foi possível concluir que: a) a vinculatividade está presente, embora com particularidades distintas, nos dois subsistemas que compõem a família jurídica ocidental; b) no subsistema anglo-saxônico, embora tenhamos diferenças entre os países que dele fazem parte, a vinculatividade, por uma questão histórico-cultural, não gera preocupações, tendo em vista que funciona aparentemente de maneira adequada; c) no subsistema romano-germânico, por sua vez, a vinculatividade judicial acarreta inquietações, uma vez que ela tem sido inserida gradualmente, sem, contudo, estabelecer um bom convívio com o sistema jurídico compilado; d) embora o $\mathrm{CPC} / 15$ tenha introduzido mecanismos que conduziram o sistema jurídico brasileiro a uma nova realidade que conjuga efetivamente o sistema codificado com a doutrina de precedentes vinculativos, resta dúvida se esta sintonia conseguirá ser compreendida pelo operadores do Direito, mormente os magistrados, e isso, em consequência, reflita num eficaz e harmônico processo hermenêutico; e) entre todas as realidades apresentadas, concluiu-se que a melhor relação entre a vinculatividade judicial e o princípio da independência dos Tribunais, resta estabelecida no modelo português, dado que ela permite ao magistrado uma ampliação de sua percepção imaginativa e, por consequência, auxilia na formação de um Direito mais coerente. Desse modo, confirma-se a hipótese formulada inicialmente na introdução deste artigo.

Considerando os levantamentos bibliográficos realizados, pode-se constatar que esta pesquisa atingiu seu objetivo geral, pois conseguiu, por meio de uma sólida linha argumentativa, revelar a melhor relação entre a vinculatividade judicial e o princípio da independência dos tribunais.

\section{REFERÊNCIAS}

ATIENZA, Manuel. As razões de direito: teoria da argumentação jurídica. Tradução Maria Cristina Guimarães Cupertino. 2. ed. Rio de Janeiro: Forense Universitária, 2014. Título original: las razones del derecho: teorias de la argumentación jurídica.

BARROSO, Luís Roberto; MELLO, Patrícia Perrone Campos. Trabalhando com uma nova lógica: a ascensão dos precedentes no direito brasileiro. Revista da AGU, v. 15, n. 3, p. 9-52. 2016.

CANOTILHO, José Joaquim Gomes. Direito constitucional e teoria da constituição. 7. ed. Coimbra: Almedina, 2003.

CARMIGNANI, Maria Cristina da Silva. O direito judiciário lusitano: os assentos da casa da suplicação. Revista da Faculdade de Direito da Universidade de São Paulo, vol. 111, p. 19-29. 2016.

CROCE, Marco. Precedente giudiziale e giurisprudenza costituzionale. Contratto e impresa, v. 22, fascicolo 4/5, p. 1.114-1.162, 2006.

GRAU, Eros Roberto. O direito posto e o direito pressuposto. 8. ed. rev. amp. São Paulo: Malheiros, 2011.

JERÓNIMO, Patrícia. Lições de direito comparado. Braga: Elsa Uminho, 2015.

MORETO, Mariana Capela Lombardi. O precedente judicial no sistema processual brasileiro. 2012. Tese (de Doutorado) -mento. Faculdade de Direito da Universidade de São Paulo, São Paulo, 2012.

NAVARRO, María Amalia Amaya. Jueces ejemplares. A medio camino: intertextos entre la literatura y el derecho. Diego Falconi (ed.). Valencia: Tirant Lo Blanch, 2019.

NEVES, Alfredo Castanheira. O instituto dos assentos e a função jurídica dos supremos tribunais. Coimbra: Coimbra Editora, 2014.

REALE, Miguel. Lições preliminares do direito. 27. ed. São Paulo: Saraiva, 2004.

REALE, Miguel. O direito como experiência: introdução à epistemologia jurídica. 2. ed. São Paulo: Saraiva, 2002.

SILVA, Paula Costa e. L'uniformazione della giurisprudenza nel diritto portoghese. Rivista di diritto processuale ${ }_{2}$ ano 68 , n. 2 , p. 409-423, 2012.

SODERO, Eduardo. Sobre el cambio de los precedentes. Isonomía, n. 21, p. 217-251, 2004.

SOLUM, Lawrence B. As virtudes e os defeitos de um juiz: um guia aristotélico para o recrutamento de juízes. Revista Julgar, n. 7, p. 11-31, 2009. 
STRÄTZ, Murilo. Precedentes vinculante à brasileira? Revista Teoria Jurídica Contemporânea, vol. 1, n. 2, p. 272-305, 2016.

STRECK, Lenio Luiz. Novo CPC decreta a morte da lei. Viva a Common Law! Conjur.2013. Disponível em: http://www.conjur. com.br/2013-set-12/senso-incomum-cpc-decreta-morte-lei-viva-common-law. Acesso em: 19 jan. 2019.

TARUFFO, Michele. Precedente e jurisprudência. Trad. Chiara de Teffé. Civilistica.com, Rio de Janeiro, ano 3, n. 2, p. 1-15, 2014. WAMBIER, Teresa Arruda Alvim. Estabilidade e adaptabilidade como objetivos do direito: civil law e common law. Revista de Processo, vol. 172, p. 121-153, 2009.

ZANINI, Leonardo Estevam de Assis. A modernização do direito civil e as cláusulas gerais. Revista do Tribunal Regional Federal da 1ㅁ região, v. 10/11, p. 36-52, 2008. 